\title{
EL RESTO DE LA VIDA O UNA NOVA RECREACIÓ DEL MITE D'ORFEU I EURÍDICE
}

\author{
ANTONI GONZÀLEZ SENMARTÍ \\ Universitat Rovira $i$ Virgili \\ antoni.gsenmarti@urv.cat \\ ORCID: 0000-0001-8181-5241
}

RESUM

Aquest article està dedicat al Dr. Pau Gilabert Barberà, una de les persones més qualificades i competents en tradició clàssica, amb motiu de la seva jubilació com a professor de la Universitat de Barcelona després de més de quaranta anys d'haver-hi impartit el seu mestratge. L'objectiu del treball és analitzar la novel·la de l'escriptora Ángeles Caso, El resto de la vida, una recreació del mite clàssic d'Orfeu i Eurídice a les acaballes del segle $\mathrm{XX}$, a partir de les múltiples referències i cites d'autors grecs i llatins que s'hi inclouen, així com del tractament que s'hi fa del mite. Es completa l'anàlisi amb una introducció sobre el polifacètic personatge d'Orfeu i la seva influència en la cultura occidental a través de les Arts.

PARAULES CLAU: Filologia clàssica, Mitologia clàssica, Tradició clàssica, Literatura comparada, Literatura espanyola contemporània, P. Gilabert.

\section{THE REST OF LIFE OR A NEW RECREATION OF ORPHEUS AND EURIDICE'S MYTH}

\section{ABSTRACT}

This paper is devoted to Mr. Pau Gilabert Barberà, Ph.D., one of the most qualified and competent personality in classical tradition, on motive of his retirement as professor at the University of Barcelona where he has been teacher and mentor since more than forty years. The purpose of this work is to analyse the novel El resto de la vida, by Ángeles Caso, a recreation of the Orpheus and Eurydice classical myth at the end of the $20^{\text {th }}$ century. This analysis is based on numerous references and citations of Greek and Latin authors included in the novel, as well as the interpretation of the myth. The study is completed with an introduction on the multifaceted character of Orpheus and its influence on Western culture through the Arts.

KEYWORDS: Classical Philology, Classical Mythology, Classical Tradition, Comparative Literature, Contemporary Spanish Literature, P. Gilabert.

at cum December canus et bruma impotens Aquilone rauco mugiet, aprica repetes Tarraconis litora tuamque Laletaniam.

Però, quan el blanc desembre i l'hivern desembridat deixin sentir els bramuls de la tramuntana, tornaràs a les costes assolellades de Tarragona i a la teva benvolguda Laletània.

Marcial, Epigrames I, 49 
No puc iniciar aquest modest i breu treball en honor de l'amic i col-lega Pau Gilabert sense agrair a la Dra. Montserrat Camps la dedicació i l'esforç esmerçats per fer realitat les Jornades de Tradició Clàssica que organitzà, amb cura i eficàcia notables, durant dos dies a la Universitat de Barcelona en homenatge a qui en va ser professor exemplar més de quaranta anys i, molt especialment, la seva condescendència en permetre'm participar-hi, encara que sigui a deshora. Els dies 31 de maig i 1 de juny vaig assistir a les susdites jornades, però no vaig poder fer-ho de forma activa, ja que compromisos personals m'impediren en aquell moment poder dedicar el temps necessari per preparar una comunicació digna de l'homenatjat. Em quedà la recança de no haver correspost com calia a l'amistat que m'ha brindat al llarg de tants anys, i la Dra. Montserrat Camps m'oferí publicar en aquest número monogràfic aquesta petita mostra d'afecte per al Pau.

Ambdós som deutors dels mateixos mestres i ambdós iniciarem la nostra carrera docent, amb pocs anys de diferència, a la Universitat de Barcelona, però ell, nascut a Tarragona, la consolidà a l'Alma Mater barcelonina mentre que jo, nascut a Barcelona, vaig optar per fer-ho a Tarragona, a la nova Universitat Rovira i Virgili. Recordo amb especial afecte els anys que coincidírem a la Junta de la Secció Catalana de la Sociedad Española de Estudios Clásicos, en els quals maldà, mitjançant múltiples i esgotadores reunions al Departament d'Ensenyament i l'organització de cursos sobre la pervivència del món clàssic amb la participació de reconeguts experts com Albert Bocos, Ricard Bofill o Juan Miquel, per consolidar la presència de l'assignatura de Cultura clàssica a l'ESO.

Pau Gilabert és filòleg, filòsof, cinèfil, melòman, filantrop, ... és el símbol de l'autèntic humanista que es troba a faltar en una societat cada vegada més deshumanitzada i individualista. Però sobretot, ha estat i continua sent un mestre per als seus deixebles i, fins i tot, per als seus companys. Prim, elegant, curós, exigent amb si mateix i amb els altres, detallista fins fregar gairebé la perfecció, és el viu retrat d'un professor d'universitat anglosaxona enamorat del Mediterrani i de la seva cultura greco-romana. Confio que, amb la seva benevolència i comprensió proverbials, disculpi la meva gosadia d'haver volgut contribuir al seu homenatge amb un exercici sobre tradició clàssica, disciplina en què precisament és un dels màxims referents. No obstant això, alguns insignes hel-lenistes espanyols, amb una visió limitada i vuitcentista de la Filologia Clàssica, li negaren el reconeixement que per justícia es mereixia. Ni tan sols el fet que el Der Neue Pauly. Enzyklopädie der Antike. Das klasischen Altertum und seine Rezeptiongeschichte dediqués cinc volums, d'un total de dinou, a la tradició clàssica els va fer canviar d'opinió. Un exemple més de l'aplicació pràctica de l'expressió castellana sostenella y no enmendalla, impropi d'universitaris.

En plantejar-me quina podria ser la meva aportació a tal efemèride, em va venir a la memòria la novel·la El resto de la vida d'Ángeles Caso, ${ }^{1}$ una recreació contemporània del mite d'Orfeu i Eurídice, que havia llegit feia anys. La

${ }^{1}$ Cf. Caso (1998). 
complexitat del personatge, en el qual s'entremesclen mite, religió, filosofia i música, temes que han estat motiu d'interès especial per a l'homenatjat, contraposada a la simplicitat de l'obra, determinà la meva decisió.

La història d'Orfeu i Eurídice es perd en la memòria dels temps entre el mite i la llegenda. Orfeu, fill d'Èagre, o del mateix déu Apol-lo, i de la musa Cal-líope, es distingia pels seus amables cants que encisaven les feres, doblegaven els arbres $i$ les plantes en actitud reverencial, i endolcien els aspres cors dels homes. Era «el pare de cants, tocador de la fòrminx ${ }^{2}$ en paraules de Píndar a la Pítica IV dedicada a Arcesilau de Cirene, vencedor en la carrera de carros. Prengué també part en l'expedició dels Argonautes a la cerca del velló d'or, en la qual, arrogantse el paper d'hortator remigum, feia que els remers batessin la impetuosa aigua del mar al so de la seva cítara ${ }^{3} \mathrm{o}$, amb el melodiós cant que emanava de la fòrminx polsada amb el plectre, lliurà els companys dels seductors cants de les sirenes. ${ }^{4}$ Però sobretot es distingí pel seu incommensurable amor per la dríada Eurídice, nimfa dels boscos tracis, la qual esposà. Un dia, mentre fugia d'Aristeu que l'empaitava, Eurídice fou mossegada per un traïdorenc escurçó que li causà la mort immediata. Res hi pogueren fer les nàiades, nimfes de les aigües, que l'acompanyaven. Orfeu, desolat, jurà baixar als inferns per tal de retornar a la vida la seva esposa, el seu amor sublim. «No lo olvides, Emma, ni la vida ni la muerte valen lo que vale el amor». ${ }^{5}$ Tal com havia previst, ni els déus infernals es van poder sostreure al poder encisador dels seus cants i accediren a la seva súplica. Orfeu inicià el camí de retorn al món dels mortals seguit d'Eurídice, però, quan ja era a punt de vèncer les lleis naturals, de destruir el dogma, la impaciència del seu amor o la por d'haver estat enganyat l'impulsaren a contravenir l'única condició que li havia estat imposada: girà el cap per contemplar la seva estimada i aquesta retornà per sempre més als inferns. De bell nou, l'ordre establert per les lleis naturals no havia pogut ésser transgredit i el

\footnotetext{
${ }^{2}$ Cf. PI. P. IV, 176-177.

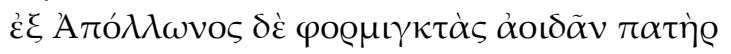

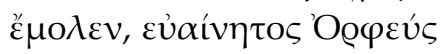

${ }^{3}$ Cf. A.R. I, 540-541.

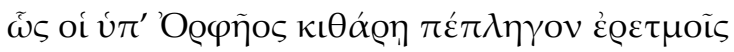

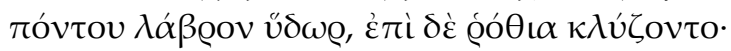

${ }^{4}$ Cf. Ibíd. IV, 903-911.

...] oí $\delta$ 'ànò vๆós

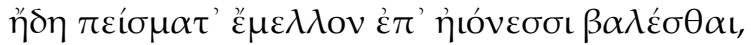

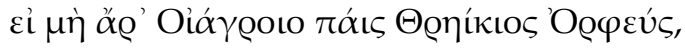

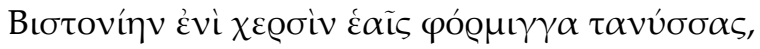

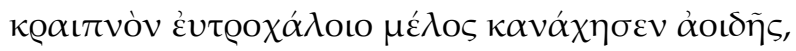

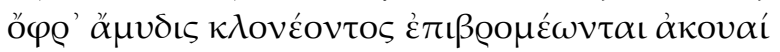

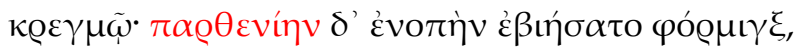

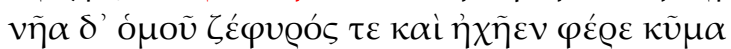

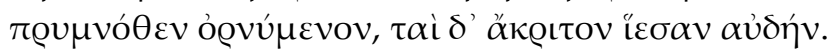

${ }^{5}$ Cf. Caso (1998: 37).
} 
dogma es mantenia intacte. Orfeu, impel-lit per l'amor de l'esposa definitivament perduda, decidí allunyar-se de tot contacte femení. No faltà qui, com Ovidi, veiés en la preservació de l'amor fidel a l'única dona de la seva vida l'ocasió d'introduir la pederàstia entre els tracis: «Ell fou encara qui ensenyà als pobles tracis de girar l'amor als tendres minyons i de collir la breu primavera de l'edat i les primeres flors». ${ }^{6}$ La vulgata el fa víctima de les dones tràcies, les quals, per despit o per gelosia, l'esquarteraren i llençaren el seu cap i la seva lira al riu. Arribats a través del mar a Lesbos, l'illa d'Alceu i Safo, de la seva tomba continuà emergint el so de la lira, que, segons Eratòstenes, es catasteritzà i esdevingué una nova constel·lació del firmament. ${ }^{7} \mathrm{D}^{\prime}$ altra banda, atès que les dones tràcies que havien sacrificat el poeta no podien quedar sense càstig, Lieu les transformà en arbres arrelats per sempre a la terra que fou testimoni del crim. ${ }^{8}$ No obstant això, Alcidamant d'Elea prefereix fer-lo víctima del llamp de Zeus per haver lliurat als homes l'escriptura i el saber que havia rebut de les Muses, emulant Prometeu, dispensador del foc als mortals:

En fi, l'escriptura la va introduir en primer lloc Orfeu, que l'havia apresa de les Muses, segons que ho mostra la inscripció de la seva tomba:

Aquí varen fer els tracis servent de les Muses Orfeu, al qual occí el que regna a les altures, Zeus, amb el llamp que tant fumeja, al fill d'Èagre, que va instruir Hèracles, perquè va descobrir per a bé dels homes l'escriptura i la saviesa. ${ }^{9}$

Però Orfeu és identificat també amb un dels poetes que precediren Homer i, com a tal, li és atribuït, de manera no fidedigna, tot un corpus de literatura

${ }^{6}$ Cf. Ov. M. x, 83-85.

Ille etiam Thracum populis fuit auctor amorem

In teneros transferre mares citraque iuuentam

Aetatis breue uer et primos carpere flores.

${ }^{7}$ Cf. ERATOSTH. 24, 45-52.

$<\tau \eta \dot{v} \delta \dot{\varepsilon} \lambda u ́ \varrho \alpha v$

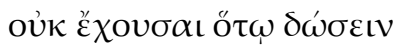

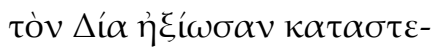

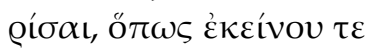

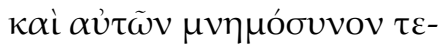

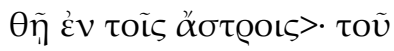

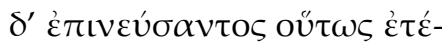

$\theta \eta$.

${ }^{8}$ Cf. Ov. M. XI, 67-84.

${ }^{9}$ Cf. AlCID. Od. 24.

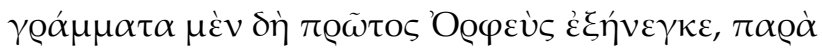

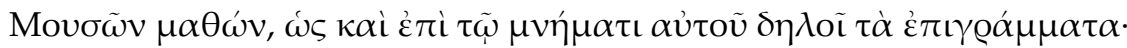

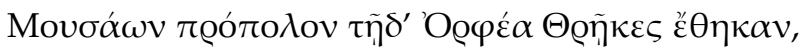

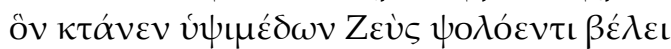

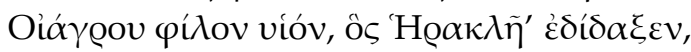

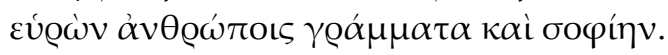


esotèrica, vinculada directament a un moviment religiós extàtic i místic anomenat orfisme, un dels pocs corrents religiosos que intentaren oposar-se al legalisme religiós tradicional col-lectiu de la Grècia arcaica. L'orfisme introduí una nova cosmogonia en què «el temps que mai envelleix» ${ }^{10}$ esdevé el nou principi; una nova teogonia representada pel mite de Zagreu, fill de Zeus i Persèfone, esquarterat pels Titans i reduït posteriorment a cendres pel raig venjador de Zeus, i pel naixement renovador de Dionís del cor de Zagreu salvat per Atena; una nova antropogonia que atorga a l'home una doble naturalesa - divina per part de Dionís i perversa per haver-se format de les cendres dels Titans-, en la qual el cos esdevé presó de l'ànima; un nou ritualisme moral en què adquireixen gran importància les purificacions i l'ascètica - una severa dieta alimentària de caràcter vegetarià, ja que la seva creença en la metempsicosi els impedia el consum de qualsevol tipus de carn -; i la introducció de l'infern com a lloc de càstig on l'ànima ha d'expiar, amb inusitada duresa, les culpes terrenals, mentre que els lliures de tota injustícia s'encaminen a les Illes dels Benaventurats. No és estrany que una religió d'aquesta naturalesa fos acollida per esperits selectes com Píndar i Plató, però menyspreada per altres que la reduïren a la condició de secta. Només en les èpoques hel-lenística i romana l'orfisme va renéixer com a fonament teològic i filosòfic de la nova religió dionisíaca, refugi de les classes socials populars allunyades de l'epicureisme i de l'estoïcisme, fins que el triomf definitiu del cristianisme representà la fi de qualsevol moviment religiós declarat pagà.

Els poetes Virgili, en la Geòrgica IV, versos 453 a 527, i Ovidi, en els llibres X, versos 1 a 85, i XI, versos 1 a 84, de les Metamorfosis, ens transmeteren la llegenda d'Orfeu a partir de la dramatització que els alexandrins havien fet del mite i, per tant, despullada de qualsevol referència misticoreligiosa. Així es difongué a través de la cultura occidental la història d'Orfeu i, molt especialment, la del tràgic amor amb la seva esposa Eurídice. Gairebé totes les Arts - la pintura, l'escultura, la poesia, el teatre, la música, la dansa, la cinematografia - han rivalitzat al llarg dels segles per fer-se seu el mite d'Orfeu, sol o acompanyat de la seva esposa Eurídice. Recordem, sense ànim d'ésser exhaustius, les pintures de Tintoretto, Rubens, Brueghel el Jove, Poussin, Luca Giordano, Tiepolo, Corot, Delacroix, Gustave Moreau, o l'escultura en bronze de Rodin. Pel que fa a les lletres, remembrem el poema Orfeo de Juan de Jáuregui, la comèdia El marido más firme de Lope de Vega, l'acte sacramental de caràcter al-legòric El divino Orfeo de Calderón de la Barca, on el mite ha estat transformat en símbol de la gràcia, el pecat i la redempció, o Lo somni de Bernat Metge, en què Orfeu exposa la seva vida i descriu l'infern a Tirèsias i al mateix autor. En són remarcables les darreres paraules d'Orfeu als tres presidents infernals - Minos, Radamant i Èac - : «No em donets repulsa, car si ho fets, sapiats que no me'n tornaré, e llavors alegrarets-

\footnotetext{
${ }^{10}$ Cf. DAM. Pr. I, 318, 1.

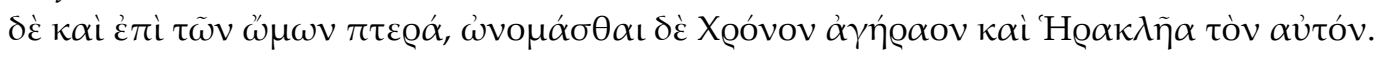


vos de la mort d'ambdosos». ${ }^{11}$ La decisió d'Orfeu és concloent: romandrà al costat de la seva estimada, viu o mort, disjuntiva plantejada ja en les Metamorfosis d'Ovidi. ${ }^{12}$ Evoquem també algunes composicions musicals que giren entorn a aquest tema: L'Orfeo de Claudio Monteverdi, inspirada en La Fabula d'Orfeo d'Angelo Poliziano; l'Orfeo ed Euridice de Christoph Gluck - qui podria oblidar l'ària d'Orfeu en l'escena primera del tercer acte quan deplora «Che farò senza Euridice? / Dove andrò senza il mio ben? / Che farò? Dove andrò? / Che farò senza il mio ben? / Dove andrò senza il mio ben? / Euridice! Euridice! / Oh dio! rispondi! rispondi! / lo son pure il tuo fedele»-; l'Orphée aux Enfers de Jacques Offenbach, de caràcter còmic fins arribar a la paròdia, que culmina en el cancan o galop infernal - «Ce bal est original d'un galop infernal donnons tous le signal»-, que ballen a l'infern totes les divinitats gairebé al final del segon quadre del segon acte, o el ballet Orpheus de Stravinskyi. Finalment no podem oblidar el Setè Art amb pel-lícules com Orphée de Jean Cocteau o l'excepcional obra de Marcel Camus, Orfeu Negro, una adaptació del drama Orfeu da Conceiçâo de Vinícius de Moraes, en què l'acció se situa en ple carnaval de Rio amb un Orfeu i una Eurídice brasilers ballant a ritme de samba la dansa de la mort. ${ }^{13}$

Aquesta introducció $m$ 'ha semblat necessària per poder fer una lectura més comprensiva de l'obra d'Ángeles Caso, una excel-lent recreació del mite d'Orfeu i Eurídice que, a les acaballes del segle $\mathrm{XX}$, se sumà a les innombrables manifestacions artístiques de tot tipus que han pres aquest mite com a element referencial al llarg de la història de la nostra civilització occidental.

Després de les dedicatòries inicials, hi trobem dues cites poètiques en llengua original, l'una de les Metamorfosis $\mathrm{d}^{\prime} \mathrm{Ovvidi}^{14} \mathrm{i}$ l'altra de Le revenant, sonet inclòs al poemari Les fleurs du mal de Charles Baudelaire, ${ }^{15}$ que, d'alguna manera, sintetitzen l'argument de la novel·la. L'obra s'inicia un 8 de març de 1997, en el camí de l'aeroport de Viena a la Prinz Eugen-Straße, on ella i ell es lliuraran mútuament els seus cossos tan llargament desitjats:

${ }^{11}$ Cf. Metge (1980: 79 i ss).

${ }^{12}$ Cf. Ov. M. x, 38-39.

Quod si fata negant ueniam pro coniuge, certum est

Nolle redire mihi; leto gaudete duorum.

${ }^{13}$ Cf. Montero (1999: 137-163).

${ }^{14}$ Cf. Ov. M. X, 11-13.

Quam satis ad superas postquam Rhodopeius auras

Defleuit uates, ne non temptaret et umbras,

Ad Styga Taenaria est ausus descendere porta;

${ }^{15}$ Cf. Baudelaire (1961: vv. 1-4).

Comme les anges à l'œil fauve,

Je reviendrai dans ton alcôve

Et vers toi glisserai sans bruit

Avec les ombres de la nuit; 
Pero, a decir verdad, sus ojos no acertaban a mirar nada que estuviese más allá del cuerpo del otro, el cuerpo tan deseado desde hacía semanas - aunque tal vez desde hacía años, y acaso, quién puede saberlo, siglos -, el cuerpo que ella y él habían imaginado tanto y que ahora, en seguida, en cuanto llegasen a casa de Emma, tocarían, lamerían, amarían, el cuerpo del que gozarían al fin arañándolo y mordiéndolo y sorbiéndoselo al otro, dejando que se derritiese el suyo propio, la carne endurecida por el deseo tantas veces aplazado. ${ }^{16}$

I finalitza el mateix dia i al mateix lloc, amb les mateixes paraules. Després de 148 pàgines ens trobem novament en el punt inicial, com si l'autora hagués volgut estructurar la composició en un estil anular o de Ringkomposition a la manera d'Homer, Píndar, Èsquil o Heròdot.

Tant el plantejament com el tractament del mite porten el segell original de l'autora. D'una banda, situa l'acció a Madrid i Viena, dues ciutats que li són familiars, malgrat els seus orígens xixonencs. Hom no pot oblidar l'interès que l'autora palesà per Elisabeth, emperadriu d'Àustria-Hongria, el qual es traduí en una biografia i una novel.la seves. ${ }^{17}$ D'altra banda, inverteix la sort dels protagonistes del mite clàssic i el camí recorregut per retrobar l'amor perdut: qui mort ara tràgicament és Orfeu, Michael, crític d'art, el qual torna a la vida des de l'avern per unir-se amb Eurídice, Emma, doctorada en Clàssiques i autora d'un treball sobre la pervivència del mite d'Orfeu i Eurídice a la cultura occidental, a causa d'un amor no satisfet ni tan sols confessat quinze anys enrere, quan ella, una adolescent, s'enamorà de l'amic de la seva mare, un home casat, ben plantat i captivador, amb qui se cità un 17 de juliol de 1982 per al següent mes de desembre a Madrid, una cita que no tindria lloc mai a causa de la prematura i tràgica mort d'ell.

Quinze anys després Michael Alcott retorna a la vida d'Emma amb el nom de Stavros Noussanis, un escultor grec el nom del qual porta implícita la idea de mort. ${ }^{18}$ La raó ens diu que els morts no ressusciten ni els fantasmes existeixen, però les coincidències se succeeixen fins al punt que Emma considera Stavros un impostor, suplantador de Michael, i Stavros acaba sent un fantasma per a ell mateix. La pregunta sobre si Michael s'havia ofegat en caure d'un veler; la ploma amb les inicials L. A., peça única feta per encàrrec a París, ara en poder seu; l'impuls sobtat de pintar un veler sacsejat per les ones afonant-se enmig de la tempesta; l'escultura d'Orfeu i Eurídice tallada amb les seves pròpies mans, de la qual no havia volgut desprendre-se'n mai, ja que era la seva obra favorita; el nom d'Erzsébet compartit per l'esposa de l'un i de l'altre; les paraules de la mare

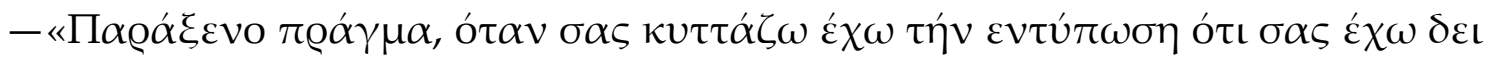

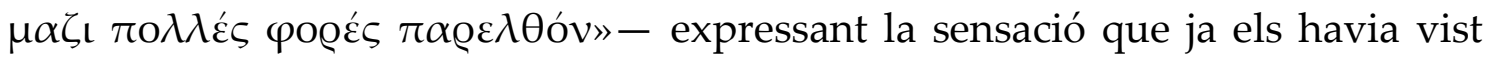
junts abans moltes vegades; la taral-la involuntària de les notes de la repetida ària

\footnotetext{
${ }^{16}$ Cf. Caso (1998: 11-12).

${ }^{17}$ Cf. Elisabeth de Austria-Hungría. Álbum privado. Barcelona: Planeta, 1998 i Elisabeth, emperatriz de Austria-Hungría. Barcelona: Planeta, 2006.

${ }^{18}$ Cal recordar que en grec stavros significa «creu».
} 
de l'Orfeo de Monteverdi, i finalment els somnis en què reviu els moments viscuts entre Michael i Emma van consolidant de forma progressiva la idea irracional del retorn de Michael i el dubte sobre la veritable identitat d'Stavros. A l'idealisme d'Emma s'hi oposen el pragmatisme de la seva amiga Christine; el diagnòstic del psiquiatra - «Su deseo es más fuerte que la realidad»- ${ }^{19} \mathrm{i}$ la radical teràpia que li proposa - «Lo que debe hacer es matar al fantasma»-20; la descripció minuciosa i realista de la mort de Michael que li relata el seu germà Henry dissipant qualsevol dubte sobre la possibilitat que s'hagués salvat, i les paraules d'Elisa, la mare d'Emma, desemmascarant Michael i posant en evidència la seva verdadera condició, que no era la d'«un hombre privilegiado», sinó la d' «un experto en la mentira y el engaño». «La realidad ... Los muertos están muertos, definitivamente fuera de la vida, y un hombre que se parece a otro hombre no tiene por qué ser el mismo», ${ }^{21}$ sentencia Stavros en la seva primera trobada amb Emma.

Però en aquest periple circular que s'inicia i finalitza el 8 de març de 1997, manca la clàusula final que segella l'obra, la clau de volta que deixa el lector immers en el buit infinit, el darrer dia, el 9 de març de 1997: «Cuando Emma se despertó por la mañana, Stavros - si es que aquel hombre era Stavros -, ya no estaba. // En el lugar que había ocupado solo quedaba el vacío. // El irremediable vacío de la ausencia». ${ }^{22}$ A l'instant ens venen a la memòria els versos de Baudelaire: «Quand viendra le matin livide, / Tu trouveras ma place vide». ${ }^{23} \mathrm{El}$ buit present al costat d'Emma era el de Michael Alcott, que havia complert la seva promesa — «Sí, yo también bajaría a los infiernos en busca de mi amada. Es más, estoy seguro de que si muriera antes que ella, volvería a la vida para encontrarla» $-{ }^{24}$, reencarnat en la persona del grec Stavros Noussanis, o tot plegat no havia estat més que un cúmul de macabres casualitats i Michael Alcott romania al fons d'algun oceà engolit per les ones del mar?

Les cites i referències al món clàssic grecollatí no falten al llarg de l'obra. Les Metamorfosis d'Ovidi són evocades en dues ocasions en el període que va de juliol a novembre de 1982, concretament els versos 29-31, ${ }^{25}$-Orfeu suplica desesperadament a les divinitats infernals que ajornin el prematur destí

\footnotetext{
${ }^{19}$ Cf. Caso (1998: 115).

${ }^{20}$ Cf. Caso (1998: 116).

${ }^{21}$ Cf. Caso (1998: 78-79).

${ }^{22}$ Cf. Caso (1998: 151).

${ }^{23}$ Cf. Baudelaire (1961: vv. 9-10).

${ }^{24}$ Cf. Caso (1998: 37).

${ }^{25}$ Cf. Ov. M. X, 29-31.

Vos quoque iunxit Amor. Per ego haec loca plena timoris

Per Chaos hoc ingens uastique silentia regni,

Eurydices, oro, properata retexite fata.
} 
d'Eurídice-, i els versos 73 a 75, ${ }^{26}$ - la consternació i el dolor d'Orfeu en veure's privat per sempre de la seva esposa-, ambdós passatges corresponents al llibre x. S'al-ludeix a Vega, l'estel principal, blanc i brillant, de la constel-lació de Lira, ${ }^{27}$ el qual contempla, enmig del silenci de l'albada, els passos de Michael i Emma, «que susurraban como culebras arrastrándose sobre la tierra del sendero flanqueado de castaños y arces». ${ }^{28}$ Es remembren els versos 242-245 del cant XIII de l'Odissea en què Atena exposa a l'heroi de gran ardit les qualitats de la seva pàtria Ítaca, no reconeguda després de tants anys d'absència. ${ }^{29} \mathrm{I}$, encara que només sigui esmentat de passada, el nom de Plató també hi és present.

Però en una obra basada en el mite d'Orfeu, el poeta i cantor per excel-lència, la música no hi podia faltar. Michael, malgrat dedicar-se a les arts plàstiques, és un amant de la música que ha substituït la lira i la fòrminx pel piano, al so del qual entona els primers i darrers mots que profereix Orfeu a l'ària del segon acte de l'òpera de Monteverdi, just quan acaba d'assabentar-se per la funesta missatgera que la seva esposa ha expirat víctima d'un escurçó que li ha clavat la seva dent verinosa: «Tu se' morta, se' morta, mia vita, ed io respiro? [...] Addio terra, addio cielo e sole, addio", tristes paraules finals d'acomiadament del món dels mortals, després que ha resolt anar a cercar la seva esposa als abismes infernals per retornar-la a la vida o romandre per sempre amb ella en companyia de la mort. Fins a sis vegades es repetiran al llarg de l'obra aquests mots que n'esdevindran el veritable leitmotiv.

El llenguatge, adequat a la temàtica de l'obra, accentua, amb els termes i les expressions emprades, el caràcter lúgubre, tenebrós, funest i obscur que irremeiablement s'associa al món dels morts: «oscura pared de piedra», «bosques negros», «seres infernales», «penumbra de las escaleras», «trueno repentino y violento», «acantilados oscuros», «sombra espesa», en poden ser alguns exemples. Se succeeixen les repeticions que contribueixen a intensificar el clímax de torbació i desassossec dels protagonistes:

\footnotetext{
${ }^{26}$ Cf. Ov. M. x, 73-75.

...] septem tamen ille diebus

Squalidus in ripam Cereris sine munere sedit;

Cura dolorque animi lacrimaequealimenta fuere.

${ }^{27}$ Cf. Caso (1998: 30).

${ }_{28}$ Cf. Caso (1998: 29).

${ }^{29}$ Cf. HOM. Od. XIII, 242-245.

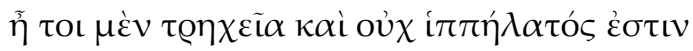

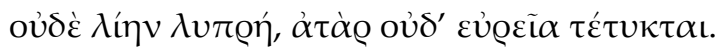

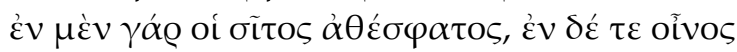

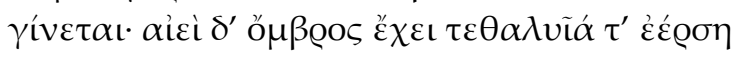


Emma lo siguió, a cierta distancia y en silencio, tratando de desvanecerse en la oscuridad, arrimada a las paredes como una criminal detrás de su víctima. $\mathrm{O}$ como una mujer enamorada detrás del hombre que la ha abandonado, y al que solo aspira a ver unos segundos, por la espalda, intentando tal vez recordar en ese extraño acercamiento el tacto tan suave de su piel, el tamaño de sus caderas que se agitaban violentas bajo ella o el sabor duro y dulce de su vientre, intentando acaso percibir el ruido de su respiración, que tanto la excitaba, olfatear igual que una perra el olor intransferible de su cuerpo. ${ }^{30}$

El mateix text, tan sols amb el canvi de subjecte, el retrobem literalment atribuït a Stavros a la pàgina 117, de la mateixa manera que el dia 8 de març inicia i conclou l'obra. També es repeteixen associats, una i altra vegada, de forma insistent, els adjectius "gris y helado», expressió gràfica de la sensació visual i tàctil de la pal-lidesa i fredor de la mort, i s'esmenten els corbs - «Los cuervos graznaban como demonios»-, aus relacionades amb les tenebres, la mort, l'infortuni, però també amb la màntica del déu Apol·lo amb qui s'associa Orfeu. Recordem que l'Orfeo de Monteverdi finalitza amb l'ascensió d'Orfeu acompanyat d'Apol·lo al cel, on gaudirà de la contemplació de la seva esposa Eurídice.

La contraposició entre el món de la llum i el món de les ombres es reflecteix en el contrast entre la descripció d'un dia d'estiu i d'un d'hivern a Viena, emfasitzant, però, la grisor i la desplaença d'aquest darrer:

El río bajaba indolente y melodioso aquel día de verano, pero no era difícil imaginarlo terrible una mañana de diciembre, una de esas mañanas del fin del mundo, cuando la lluvia cae haciéndonos creer que toda el agua eternamente posible dentro de las nubes se ha concentrado en unas horas, y el viento azota los árboles desnudos y ruge entre las cortadas del desfiladero, y el rastro de la luz dorada parece haberse borrado de la luz del mundo, dejando solo una leve huella que apenas alcanza a desvelar las formas de las cosas, fundiendo las unas dentro de las otras, desalojándolas de la materia sólida. Una de esas mañanas en las que se diría que la realidad no existe. ${ }^{31}$

Per últim, la vegetació, en les seves més variades formes, és present de forma reiterada en l'obra, marc testimonial de la transformació en arbres de les dones tràcies que esquarteraren Orfeu: «Entre la niebla, los altos árboles del parque de Lainz parecían figuras de alguna cabalgata misteriosa y evanescente, leves formas sin raíces del reino veloz de las apariencias». ${ }^{32}$

\footnotetext{
${ }^{30}$ Cf. Caso (1998: 73).

${ }^{31}$ Cf. Caso (1998: 15-16).

${ }^{32}$ Cf. Caso (1998: 66).
} 
En les darreres paraules d'Elisa a la seva filla Emma, — «Quizá fuera por lo mucho que lo quería, pero siempre pensé que Michael iba a envejecer bien. Que algún día tendría que importarle de verdad una mujer. Que aprendería a querer...»— ${ }^{33}$ em sembla escoltar l'eco de les paraules de Paul Diel: «Símbolo del deseo de armonización y concentración creadora, Eurídice está, por esa razón, en oposición directa a la multiplicación dionisíaca de los deseos: a las ménades. Y en el plano directo, concreto, a la multitud de mujeres secretamente deseadas». ${ }^{34}$

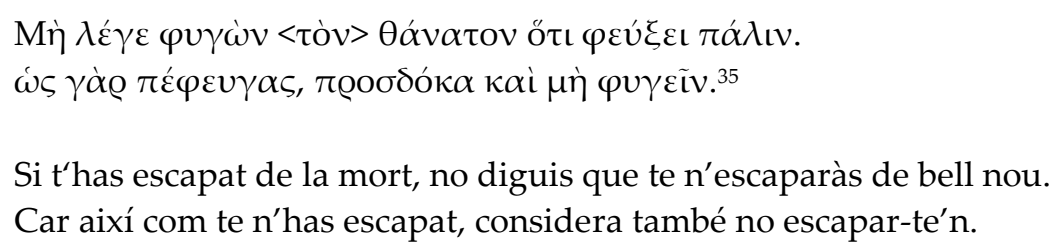

\section{BIBLIOGRAFIA}

AlCID = AlCIDAMANT D'Elea (2014), Odisseu. (Contra Palamedes, per traïció), Barcelona, Fundació Bernat Metge.

A. R. = APOLLONII RHODII (1961), Argonautica, Oxford, Clarendon Press.

BAUDELAIRE, CH. (1961), Les fleurs du mal : Le revenant, Paris, Éditions Garnier, 70.

CASO, Á. (1998), El resto de la vida, Barcelona, Planeta.

DAM. $=$ DAMASCIUS (1889), De Principiis, Paris, Klincksieck.

DIEL, P. (1976), El simbolismo en la mitología griega, Barcelona, Labor.

ERATOSTH. = ERATOSTHENES (1897), Mythographi Graeci 3.1., Leipzig, Teubner.

HOM. $=$ HOMERI (1919²), Opera, Tomus IV Odysseae libros XIII-XXIV continens, Oxford, Clarendon Press.

MART. = VALERI MARCIAL, M. (1949), Epigrames, Barcelona, Fundació Bernat Metge. MENANDRI ET PHILISTIONIS SENTENTIAE (1964), Menandri sententiae, Leipzig, Teubner. Metge, B. (1980), Lo Somni: Llibre Terç, Barcelona, Edicions 62 i «la Caixa».

Montero Montero, M. (1999), «Orfeo y Eurídice», a Amores Míticos, Fernández de Mier,

E. i Piñero, F. (eds.), Madrid, Ediciones Clásicas.

Ov. = OvIDI (1929-1932), Les Metamorfosis, 3 Vols., Barcelona, Fundació Bernat Metge. PI. = PINDARI $\left(1947^{2}\right)$, Carmina cum fragmentis, Oxford, Clarendon Press.

${ }^{33}$ Cf. Caso (1998: 147).

${ }^{34}$ Cf. Diel (1976: 132).

${ }^{35} \mathrm{Cf}$. Menandri et Philistionis Sententiae, III, 27-28. 